\title{
Activation of Beryllium-Implanted GaN by Two-Step Annealing
}

Yuejun Sun, Leng Seow Tan, Soo Jin Chua and Savarimuthu Prakash Centre for Optoelectronics, Department of Electrical Engineering,

National University of Singapore, 10 Kent Ridge Crescent, Singapore 119260,

Republic of Singapore

\begin{abstract}
For the first time, $p$-type doping through beryllium implantation in gallium nitride was achieved by using a new annealing process, in which the sample was first annealed in forming gas $\left(12 \% \mathrm{H}_{2}\right.$ and $\left.88 \% \mathrm{~N}_{2}\right)$, followed by annealing in pure nitrogen. Variable temperature Hall measurements showed that sheet hole concentrations of the annealed samples were about $1 \times 10^{13} \mathrm{~cm}^{-2}$ with low hole mobilities. An ionization energy of 127 $\mathrm{meV}$ was estimated with a corresponding activation efficiency of $\sim 100 \%$. SIMS results revealed a relationship between the enhanced diffusion of $\mathrm{Be}$ and activation of the acceptors.
\end{abstract}

\section{INTRODUCTION}

A critical issue in the fabrication of gallium nitride $(\mathrm{GaN})$ devices is the achievement of significant and controllable $p$-type doping. It still remains a challenge because of the high $n$-type autodoping background present in as-grown materials and the large ionization energy of acceptors, such as $\mathrm{Mg}, \mathrm{Zn}$ and $\mathrm{Cd} .{ }^{1}$ The principal $p$-type dopant used for GaN is $\mathrm{Mg}$ with an ionization energy of $150-165 \mathrm{meV}{ }^{2}$ Such a large acceptor ionization energy is problematic and two to three orders of magnitude higher atomic doping level of $\mathrm{Mg}$ must be incorporated into $\mathrm{GaN}$ in order to achieve the desired hole concentration at room temperature. ${ }^{3}$ Although $\mathrm{Zn}$ and $\mathrm{Cd}$ are conventionally used as $p$-type dopants in the growth of other III-V compounds, Strite ${ }^{4}$ suggested that the $d$-electron core relaxation in these elements is partially responsible for the enhanced depth, making efficient doping at room temperature impossible.

Beryllium (Be) was thought to be a shallower acceptor in $\mathrm{GaN}$ due to its large electronegativity and the absence of $d$-electrons. Ab initio calculations ${ }^{5}$ predicted that $\mathrm{Be}$ behaves as a rather shallow acceptor in $\mathrm{GaN}$, with a thermal ionization energy of $60 \mathrm{meV}$ in wurtzite GaN. More evidence from photoluminescence (PL) spectra revealed that Be acts as an acceptor with an optical ionization energy ranging from $90-100 \mathrm{meV},{ }^{6,7} 150$ $\mathrm{meV},{ }^{8}$ to $250 \mathrm{meV} .{ }^{9}$ However, the size of Be atoms is so small that it seems more probable for them to stay at interstitial sites $\left(\mathrm{Be}_{\mathrm{int}}\right)$ rather than at substitutional sites $\left(\mathrm{Be}_{\mathrm{Ga}}\right)$ in $\mathrm{GaN}$. Theoretical calculations ${ }^{10}$ also pointed out that the formation energy of $\mathrm{Be}_{\text {int }}$ is much less than that of $\mathrm{Be}_{\mathrm{Ga}}$. Interstitial Be behaves like a double donor so that selfcompensation is a significant drawback for the use of Be as an acceptor. That is why there is almost no achievement of electrical activiation of Be-doped $\mathrm{GaN}$, except for Brandt $e t$ $a l$. who obtained high mobility $p$-type materials from $\mathrm{Be}-\mathrm{O}$ codoped cubic $\mathrm{GaN}$ by molecular beam epitaxy. ${ }^{11}$

In this paper, we introduce a new annealing process in which the Be-implanted GaN wafers were first annealed in forming gas, followed by annealing in a pure $\mathrm{N}_{2}$ atmosphere. 
Electrical activation of Be-implanted GaN was observed for the first time. The results confirmed the low activation energy of $\mathrm{Be}$ as an acceptor in $\mathrm{GaN}$ and also showed the possibility of $p$-type doping by Be implantation.

\section{EXPERIMENT}

The undoped $\mathrm{GaN}$ layers used in the experiments were $2 \mu \mathrm{m}$ thick and grown on $c$ plane sapphire substrates by MOCVD in a multiwafer rotating disk reactor at $1040{ }^{\circ} \mathrm{C}$, with a $\sim 20 \mathrm{~nm} \mathrm{GaN}$ buffer layer grown at $530{ }^{\circ} \mathrm{C}$ in advance. The background $n$-type carrier concentrations were around $9 \times 10^{16} \mathrm{~cm}^{-3}$. The as-grown layers had featureless surfaces and were transparent with a strong near band-edge luminescence at $3.44 \mathrm{eV}$ at room temperature. Be was implanted ${ }^{+}$into two pieces of the undoped $\mathrm{GaN}$ wafer at 40 $\mathrm{keV}$. The doses were $3 \times 10^{14} \mathrm{~cm}^{-2}$ and $1 \times 10^{15} \mathrm{~cm}^{-2}$, respectively. Samples of dimensions $6 \times 6 \mathrm{~mm}^{2}$ were cut from the wafers. Annealing was performed in a RTP system equipped with halogen-tungsten lamps. One set of the implanted samples was sequentially annealed at $900-1100{ }^{\circ} \mathrm{C}$ for $45 \mathrm{~s}$ in flowing $\mathrm{N}_{2}$ according to a face-to-face geometry. The other set of implanted samples was annealed in forming gas $\left(12 \% \mathrm{H}_{2}\right.$ and $\left.88 \% \mathrm{~N}_{2}\right)$ first at temperatures ranging from 500 to $1100{ }^{\circ} \mathrm{C}$ and then in flowing $\mathrm{N} 2$. Hall effect measurements were conducted at room and variable temperatures with a magnetic field of 0.32 Tesla. Indium dots were alloyed at the corners of each sample according to the Van der Pauw geometry. Secondary ion mass spectrometry (SIMS) analyses were carried out in a CAMECA ims-6f microscope. $\mathrm{An}_{2}{ }^{+}$beam of $200 \mathrm{nA}$ and $8 \mathrm{keV}$ impact energy was used to sputter the samples. The quantification of the $\mathrm{H}$ concentration was not available due to the lack of reference. However, the $\mathrm{H}^{+}$intensities in all the samples have been normalized with respect to $\mathrm{N}^{+}$, and therefore were comparable.

\section{RESULTS AND DISCUSSION}

From the variable temperature Hall measurements, a plot of the sheet carrier concentration/ temperature product $\left(p_{s} T^{-3 / 2}\right)$ vs. reciprocal temperature can be constructed. Figure 1 shows such a plot for a Be-implanted GaN sample annealed at $600{ }^{\circ} \mathrm{C}$ and $10 \mathrm{~s}$ in forming gas first, followed at 1100 ${ }^{\circ} \mathrm{C}$ and $45 \mathrm{~s}$ in $\mathrm{N}_{2}$. As shown by Gotz et al., ${ }^{12}$ the normal slope analysis in a linear region of the carrier concentration alone versus reciprocal temperature data could yield around $1 / 3$ more than the real activation energy. We think the Arrhenius plot of the sheet carrier

\footnotetext{
${ }^{+}$The implantation was performed by Implantation Science Corporation, Wakefield, MA, USA
} 
concentration/temperature product vs. the inverse temperature is more appropriate to estimate the ionization level of Be. Under nondegenerate conditions, the hole concentration can be expressed as the following relation: $p \propto p_{o} T^{3 / 2} \exp \left(-E_{a} / k T\right)$, where $p_{o}$ is the acceptor concentration and $\mathrm{E}_{\mathrm{a}}$ is the activation energy of the acceptors. So, $\ln (p T$

${ }^{3 / 2}$ ) should be proportional to the inverse $T$. Due to non-uniformity of the implanted atoms in the substrate layer, here we use the sheet carrier concentration $p_{s}$ to plot, instead of $p$. From Figure 1, the ionization energy of $\mathrm{Be}$ in $\mathrm{GaN}$ is calculated to be $127 \mathrm{meV}$, which is lower than that of $\mathrm{Mg}$ and $\mathrm{Ca}$ reported for implanted $\mathrm{GaN}^{2,13}$ Based on the ionization energy estimated above, only $0.73 \%$ of Be acceptors would be ionized at room temperature. The activation efficiency can thus be estimated to be around $100 \%$ for this sample (considering $p_{\mathrm{s}}=2.14 \times 10^{13} \mathrm{~cm}^{-2}$ at room temperature), if the activation efficiency is defined as sheet carrier concentration/(dosexionization rate). The activation efficiency of $\mathrm{Be}$ is similar to that of $\mathrm{Ca}{ }^{13}$

The results of room temperature Hall measurement are summarized in Table I. Several remarkable things should be pointed out. (i) The implanted samples without postannealing process still showed $n$-type conductive characteristics with a bit of reduction in electron concentrations, unlike most implanted GaN samples which had high resistivities due to defect states within the band gap that act as traps for the carriers. This may be the results of less damage produced by the smaller mass of Be, low implantation energy (40 $\mathrm{KeV}$ ) and the resistance of $\mathrm{GaN}$ materials to damage by implantation, with considerable dynamic recovery of implantation-induced disorder. High-resolution x-ray diffractometry (HRXRD) was performed to detect the implantation damage. There was no difference in the rocking curves between the as-grown sample and the as-implanted sample. However, it should be noted that HRXRD results could not demonstrate conclusively that the implantation damage was not significant because HRXRD is not very sensitive to implant damage for the lower dose

TABLE I. Room temperature Hall effect data of GaN samples

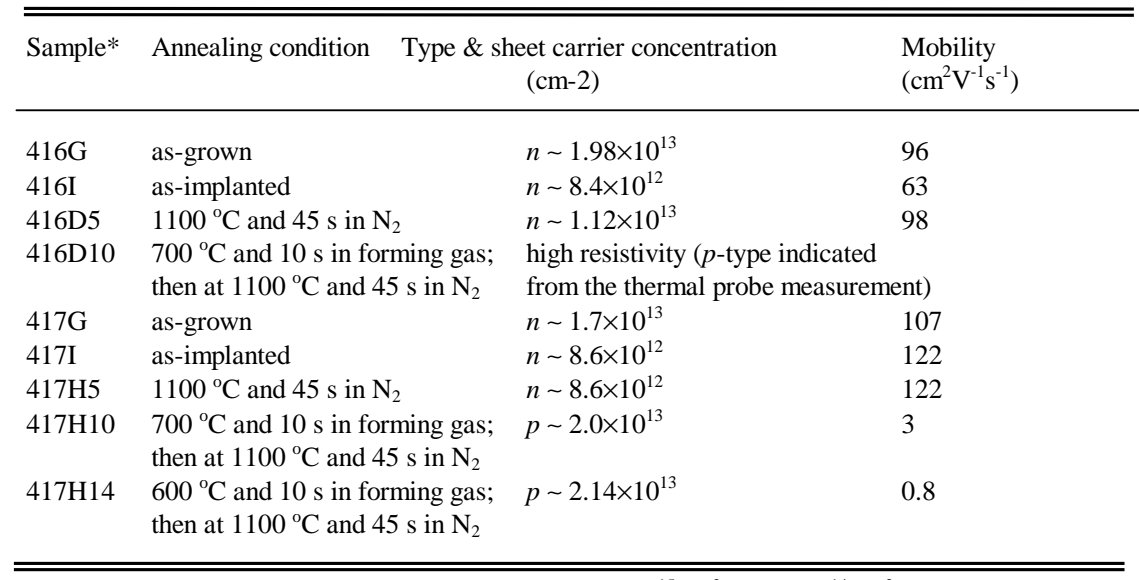

*The doses for Sample 416 series and 417 series are $1 \times 10^{15} \mathrm{~cm}^{-2}$ and $3 \times 10^{14} \mathrm{~cm}^{-2}$, respectively 
sample. (ii) The new annealing process for the high dose $\left(1 \times 10^{15} \mathrm{~cm}^{-2}\right)$ implanted samples produced high-resistivity material. This is probably because, besides the native donors and interstitial Be, more defects were introduced by the higher dose implantation, which compensated the effects of the activated acceptors. This is similar to the case of high $\mathrm{Mg}$ doping in GaN. ${ }^{14}$ (iii) $p$-type doping was achieved for the lower dose $\left(3 \times 10^{14} \mathrm{~cm}^{-2}\right)$ implanted samples, with a sheet hole concentration around $10^{13} \mathrm{~cm}^{-2}$. To confirm the realization of $p$-type doping, thermal probe measurements were performed. We used Mgdoped $p$-type $\mathrm{GaN}$ and undoped $n$-type $\mathrm{GaN}$ samples as references. The results were consistent with the Hall measurements, thus confirming that the Be-implanted and annealed samples were indeed $p$-type.

Figure 2 depicts the SIMS profiles of Be and $\mathrm{H}$ for different samples. Fig.2(a) shows the depth profiles of $\mathrm{Be}$ and $\mathrm{H}$ in the as-grown sample. The measured $\mathrm{Be}$ concentration was due to a background level noise governed by the intrinsic impurity and the detection limit of our SIMS measurement conditions. The depth profile of $\mathrm{Be}$ in the as-implanted sample exhibited a peak at a depth of $120 \mathrm{~nm}$ as shown in Fig.2(b). The $\mathrm{H}$ profile in this sample was almost the same as that in the as-grown sample. There was no significant channeling tail of $\mathrm{Be}$, unlike that in the Be as-implanted samples $(45 \mathrm{keV}, 5 \times$ $10^{14} \mathrm{~cm}^{-2}$ ) in REF 15 . We think the differences are from the implantation process, such as beam divergence or other random factors, but probably not from some factors like energy and dose, which are similar to ours. After annealing at $1100{ }^{\circ} \mathrm{C}$ for $45 \mathrm{~s}$, the peak was nearer the surface than that in the as-implanted sample. The projected range was $73 \mathrm{~nm}$ (Fig.2(c)). The $\mathrm{H}$ profile remained similar. The Be redistribution in this case can be attributed to defect-assisted diffusion. ${ }^{16}$ It is noted that some groups ${ }^{15,17}$ did not see measurable redistribution of $\mathrm{Be}$ in GaN. In Fig. 2(d), the Be and $\mathrm{H}$ profiles of the sample annealed with the new process were substantially different from the others. In the top 230 $\mathrm{nm}$ layer, the Be profile showed a plateau-like shape, at a concentration of $\sim 1.2 \times 10^{19} \mathrm{~cm}^{-3}$.

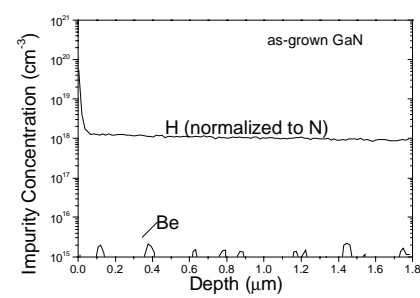

Fig.2 (a)

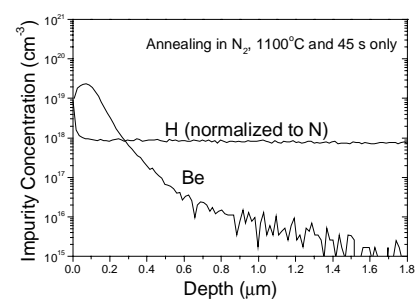

Fig. 2 (c)

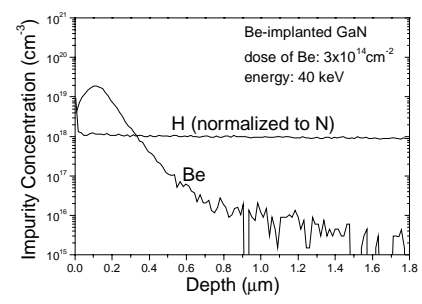

Fig.2 (b)

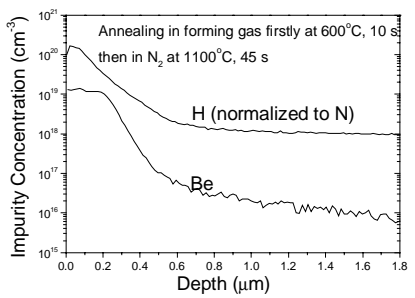

Fig. 2 (d) 
At depths beyond $0.5 \mu \mathrm{m}$, the Be level was much higher than that in the as-implanted sample and $\mathrm{N}_{2}$-annealed sample, indicating enhanced in-diffusion of Be. In addition, accumulation of $\mathrm{H}$ was observed in the near-surface region, where the $\mathrm{H}$ concentration was one to two orders of magnitude higher than the background level. From the study of thermal stability of hydrogen in ${ }^{2} \mathrm{H}$-implanted $p$-type $\mathrm{GaN},{ }^{18}$ the diffusion of the deuterium started at a lower temperature of about $500-700{ }^{\circ} \mathrm{C}$ and $\mathrm{Mg}-\mathrm{H}$ complexes were formed, but these were completely gone by $1000{ }^{\circ} \mathrm{C}$. However, for our samples, even an $1100{ }^{\circ} \mathrm{C}$ annealing could not entirely break the bonds of potential $\mathrm{H}$ complexes and remove the $\mathrm{H}$.

From the analysis of Hall and thermal probe measurements, it seems that there exists some relationship between the enhanced diffusion of Be and the activation of the acceptors, similar to the case of $\mathrm{Zn}$ diffusion and the optical activation of acceptors in $\mathrm{Zn}$-implanted $\mathrm{GaN}{ }^{19}$

The effect of the new annealing process on Be activation can be tentatively explained as follows. After implantation, there are many Be atoms at interstitial sites, which could easily form a large concentration of substitutional-interstitial (SI) Be-related complexes. Annealing in an atmosphere containing hydrogen might cause the formation of $\mathrm{Be}_{\text {int }}-\mathrm{H}$ complexes first. The $\mathrm{Be}_{\text {int }}-\mathrm{H}$ complexes can move into $\mathrm{Ga}$ vacancies $\left(\mathrm{V}_{\mathrm{Ga}}\right)$ more easily and are then converted to $\mathrm{Be}_{\mathrm{Ga}}-\mathrm{H}-\mathrm{N}$ complexes. The energy required to break the $\mathrm{H}$-bonds in the $\mathrm{Be}_{\mathrm{Ga}}-\mathrm{H}-\mathrm{N}$ complexes might be lower than that needed to move the $\mathrm{Be}_{\text {int }}$ directly to the substitutional sites during conventional annealing in $\mathrm{N}_{2}$ only. The subsequent annealing in flowing $\mathrm{N}_{2}$ will then depassivate the complexes and activate the implanted Be. An independent inference from a first-principles calculation ${ }^{20}$ also pointed out that an annealing stage in an ambient including hydrogen before conventional annealing in $\mathrm{N}_{2}$ would improve activation of $p$-type dopants in GaN.

\section{CONCLUSION}

In conclusion, we present a new annealing process and have observed significant improvement of activation in Be-implanted GaN for the first time, demonstrate the possibility of $p$-type doping in $\mathrm{GaN}$ through $\mathrm{Be}$ implantation and confirm that $\mathrm{Be}$ has a shallow acceptor level in GaN. Further optimization of annealing conditions will be investigated to improve the properties of Be-implanted GaN.

\section{ACKNOWLEDGEMENTS}

Yuejun Sun would like to thank the National University of Singapore for providing him with a Research Scholarship and Dr. Liu Wei for discussions. The author would also like to acknowledge Dr. David Look for useful discussions and manuscript preparation. This work is supported by the Singapore National Science and Technology Board through a grant NSTB/17/2/3 GR6471.

\section{REFERENCE}

1. S. Strite and H. Morkoc, J. Vac. Sci. Tech. B, 10, 1237 (1992)

2 I. Akasaki, H. Amano, M. Kito and K. Hiramatsu, J. Lumin., 48/49, 666 (1991)

3. J. W. Orton, Semicond. Sci. Tech., 10, 101 (1995) 
4. $\quad$ S. Strite, Jpn. J. Appl. Phys., 33, 699 (1994)

5. F. Bernardini, V. Fiorentini, and A. Bosin, Appl. Phys. Lett., 70, 2990 (1997)

6. D. J. Dewsnip, A. V. Andrianov, I. Harrison, J. W. Orton, D.E. Lacklison, G. B. Ren, S.E. Hopper, T. S. Cheng, and C. T. Foxon, Semicond. Sci. Tech., 13, 500 (1998)

7. F. J. Sanchez, F. Calle, M. A. Sanchez-Garcia, E. Calleja, E. Munoz, C. H. Molly, D. J. Somerford, F. K. Koschnick, K. Michael, and J. M. Spaeth, MRS Internet J. of Nitride Semicon. Research, V3, Article 19 (1998)

8. C. Ronning, E. P. Carlson, D. B. Thomson, and R. F. Davis, Appl. Phys. Lett., 73, $1622(1998)$

9. A. Salvador, W. Kim, O. Aktas, A.Botchkarev, Z. Fan, and H. Morkoc, Appl. Phys. Lett., 69, 2692 (1996)

10. J. Neugebauer and C. G. Van De Walle, Appl. Phys. Lett., 85, 3003 (1999)

11. O. Brandt, H. Yang, H. Kostial, and K. H. Ploog, Appl. Phys. Lett., 69, 2707 (1996)

12 W. Gotz, N. M. Johnson, C. Chen, H. Liu, C. Kuo and W. Imler, Appl. Phys. Lett., 68, 3144 (1996)

13 J.C. Zolper, R. G. Wilson, S. J. Pearton and R. A. Stall, Appl. Phys. Lett., 68, 1945(1996).

14 L. Eckey, U. von Gfug, J. Holst, A. Hoffmann, A. Kaschner, H. siegle, C. Thomsen, B. Schineller, K. Heime, M. Heuken, O. Schon and R. Beccard, J. Appl. Phys., 84, 5828 (1998)

15 J. C. Zolper, in : GaN and Related Materials, Ed. S. J. Pearton (Gordon and Breach, New York, 1997) ch.12

16 R. G. Wilson, J. M. Zavada, X.A. Cao, R.K. Singh, S. J. Pearton, H. J. Guo, S. J. Pennycook, M. Fu, J.A. Sekhar, V. Scarvepalli, R. J. Shul, J. Han, D. J. Rieger, J. C. Zolper and C. R. Abernathy, J. Vac. Sci. Technol., A 17, 1226 (1999).

17 C. Ronning, K. J. Linthicum, E. P. Carlson, P. J. Hartlieb, D. B. Thomson, T. Gehrke and R. F. Davis, MRS Internet J. Nitride Semicond. Res., 4S1, G3.17 (1999)

18 S. J. Pearton, R. G. Wilson, J. M. Zavada, J. Han and R. J. Shul, Appl. Phys. Lett., 73, 1877 (1998)

19 T. Suski, J. Jun, M. Leszczynski, H. Teisseyre, S. Strite, A. Rockett, A. Pelzmann, M. Kamp and K. J. Ebeling, J. Appl. Phys., 84, 1155 (1998)

20 F. A. Reboredo and S. T. Pantelides, Phys. Rev. Lett., 82, 1887 (1999) 